\title{
Increase in plasma $\beta$ endorphins precedes vasodepressor syncope
}

David R Wallbridge, Halina E MacIntyre, Christina E Gray, Martin A Denvir, Keith G Oldroyd, Alan P Rae, Stuart M Cobbe
Abstract

Background-Endogenous opioids have a tonic inhibitory effect on sympathetic tone and have been implicated in the pathophysiology of vasodepressor syncope. Plasma $\beta$ endorphin concentrations increase after vasodepressor syncope induced by exercise or by fasting.

Aims-To take frequent samples for plasma $\beta$ endorphin estimation during tilt testing, and to determine whether plasma $\beta$ endorphin increased before the start of syncope.

Patients -24 patients undergoing tilt testing for investigation of unexplained syncope.

Setting-Tertiary referral centre.

Methods-Blood samples were obtained during $70^{\circ}$ head up tilt testing. Plasma $\beta$ endorphin concentrations were estimated by radioimmunoassay (mean(SD) pmol/1).

Results-Patients with a positive test showed a rise in $\beta$ endorphin concentrations before syncope baseline $4.4(1.5) v$ start of syncope $8 \cdot 5(3 \cdot 1), p<0 \cdot 002)$. In contrast, patients with a negative test showed no change in $\beta$ endorphin concentrations (baseline $3 \cdot 4(1 \cdot 0) v$ end of test $4 \cdot 5(2 \cdot 3)$, NS). After syncope all patients showed a large secondary increase in $\beta$ endorphins $(32 \cdot 3(18 \cdot 6))$.

Conclusion-An increase in plasma $\beta$ endorphins precedes vasodepressor syncope. This finding supports a pathophysiological role for endogeneous opioids.

(Br Heart f 1994;71:446-448)

Department of Medical Cardiology D R Wallbridge

M A Denvir

K G Oldroyd

A P Rae

$S M$ Cobbe

Department of

Pathological

Biochemistry, Royal

Infirmary, Glasgow

H E MacIntyre

C E Gray

Correspondence to:

Dr D R Wallbridge,

Department of Medical

Cardiology, Royal Infirmary,

10 Alexandra Parade,

Glasgow G31 2ER.

Accepted for publication

22 November 1993
Syncope is a common medical problem with multiple potential causes. Vasodepressor (neurocardiogenic) syncope is being increasingly recognised with the introduction of head up tilt testing. ${ }^{1}$ Although the pathophysiology of this condition is not fully elucidated, hypotension probably results from a sudden reduction in or cessation of sympathetic activity. ${ }^{2}$ Endogenous opioids seem to exert a tonic inhibitory effect on sympathetic responses to orthostatic stress, and have been implicated in the mechanisms underlying syncope. ${ }^{3}$ Plasma $\beta$ endorphins have previously been shown to rise in patients after vasodepressor syncope but it is unclear whether this represents a primary or secondary phenomenon. ${ }^{4}$ Therefore, we performed frequent blood sampling for plasma $\beta$ endorphin estimation during tilt tests, to establish whether plasma $\beta$ endorphins are released before the onset of syncope.

\section{Patients and methods}

TILT TEST

We studied 24 consecutive patients (mean (range) age 54.5 (18-77)) undergoing tilt tests for the investigation of unexplained syncope. Table 1 shows the clinical characteristics of the patients. Regular medication was continued before the test. All tests were performed in the fasting state between 0930 and 1230. Patients were tilted $70^{\circ}$ head upwards for up to 40 minutes: an angle of at least $60^{\circ}$ was required for adequate test sensitivity. ${ }^{5}$ Non-invasive measurement of blood pressure was performed with Finapress (continuous) and Dinamapp (intermittent) devices. An antecubital venous cannula, inserted $15 \mathrm{~min}$ utes before the test, allowed frequent blood sampling. Aliquots of $20 \mathrm{ml}$ were obtained at baseline, and then every 10 minutes, or at the start of symptoms, and after syncope (a maximum of $120 \mathrm{ml}$ per test).

\section{ENDORPHIN ASSAY}

$\beta$ Endorphin was measured by an in house liquid phase radioimmunoassay after extraction from plasma with C18 Sep-Pak cartridges. The primary antiserum cross reacts by $2 \%$ with human $\beta$ lipotrophin (Peninsula Laboratories) and by $<0.01 \%$ with other related peptides. The sensitivity of the assay is $2 \mathrm{pmol} / \mathrm{l}$. The within batch coefficient of variation over the concentration range 12 to 60 $\mathrm{pmol} / 1$ was $5 \%$, and $10 \%$ at $7 \mathrm{pmol} / \mathrm{l}$. The between batch variation for corresponding ranges was $8 \%$ and $12 \%$. Results are given as mean(SD) plasma $\beta$ endorphin concentrations expressed as pmol/l.

\begin{tabular}{lcc}
$\begin{array}{l}\text { Table } 1 \\
\text { result }\end{array}$ & Clinical characteristics of patients by tilt test \\
\hline & Positive tilt test & Negative tilt test \\
\hline No & 10 & 14 \\
M/F & $7 / 3$ & $6 / 8$ \\
Age (yr) & $54 \cdot 5(15 \cdot 9)$ & $55 \cdot 5(14 \cdot 5)$ \\
Previous myocardial & 1 & \\
$\quad$ infarction & 3 & 4 \\
Hypertension & 1 & 2 \\
$\beta$ Blocker or disopyramide & 1 & \\
\hline
\end{tabular}


Figure 1 Plasma $\beta$ tilt test (syncope $=$ time $0)$. Broken line is upper limit of normal

Figure 2 Plasma $\beta$ endorphin concentrations in patients with a negative tilt test. Broken line is upper limit of normal. endorphin concentrations in patients with a positive
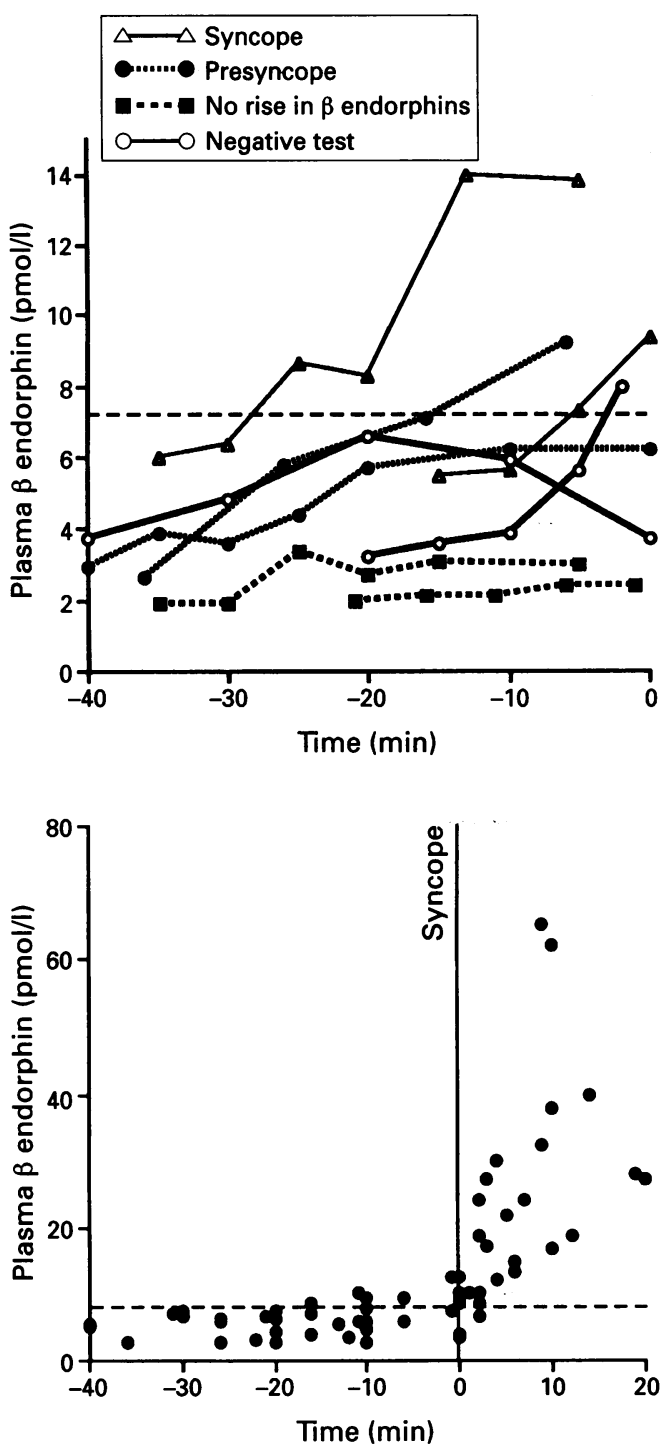

Figure 3 Plasma $\beta$ endorphin concentrations before and after syncope. Broken line is upper limit of normal.

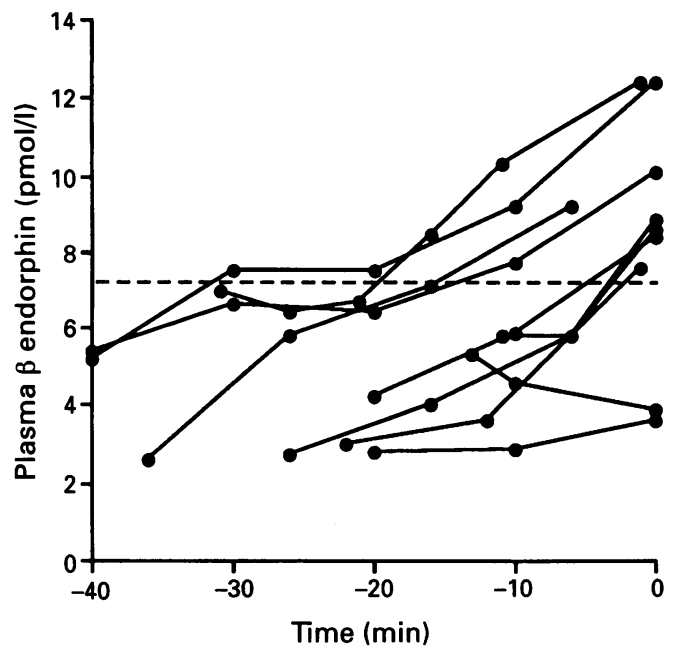

Figure 4 Plasma $\beta$ endorphin responses on repeat tilt tests in four patients with vasodepressor syncope. Concordant responses include syncope, presyncope on repeat testing, no rise in plasma $\beta$ endorphins before two vasodepressor responses. After successful treatment with disopyramide one patient had a negative test (syncope or end of test = time 0 ). Broken line is upper limit of normal.

In contrast, the group of patients with a negative test showed little change in plasma $\beta$ endorphin concentrations during the haemodynamic stress of tilting (baseline $3 \cdot 4(1 \cdot 0) v$ end of test $4 \cdot 5(2 \cdot 3)$, NS). Only two of 14 patients with a negative test showed a rise in plasma $\beta$ endorphin concentrations to above the upper limit of normal (fig 2).

When samples were obtained during syncope, four patients showed a small fall in plasma $\beta$ endorphin concentrations corresponding to the nadir of blood pressure. This fall was not accompanied by parallel changes in human growth hormone, as might be expected from pituitary hypoperfusion. After syncope all patients showed a large secondary increase in plasma $\beta$ endorphins $(32 \cdot 3(18 \cdot 6)$, (fig 3).

\section{REPRODUCIBILITY OF THE ENDORPHIN} RESPONSE

Figure 4 shows the plasma $\beta$ endorphin response during repeat tilt testing in four patients with vasodepressor syncope. The concordant responses include one patient with syncope, one patient with presyncope on repeat tests, and one patient with no rise in plasma $\beta$ endorphins before vasodepressor syncope on two occasions. Successful treatment with disopyramide in one patient resulted in a negative tilt test with no sustained rise in $\beta$ endorphin.

HAEMODYNAMIC RESPONSE BEFORE SYNCOPE

Table 2 shows the haemodynamic response to tilt tests. Although there was a wide scatter of results, and a borderline significant rise in heart rate before syncope in the positive test group, no significant differences existed at any time between the heart rates or blood pressures in the positive or negative test groups.

Discussion

Tilt testing has facilitated the diagnosis of $8.5(3.1), \mathrm{p}<0.002)$. A rise in plasma $\beta$ endorphin concentrations to above the upper limit of normal $(7 \cdot 2)$ occurred before the start of symptoms in eight of these 10 patients (fig 1 ).

Patients with a positive test (nine vasodepressor, syncope; one presyncope: mean time to onset $26 \cdot 1 \mathrm{~min}$ ) showed a significant rise in plasma $\beta$ endorphin concentrations before 
Table 2 Haemodynamic response to tilt tests (mean $(S D))$

\begin{tabular}{|c|c|c|c|}
\hline$n$ & $\begin{array}{l}\text { Heart rate } \\
\text { (beats } / \text { min) }\end{array}$ & $\begin{array}{l}\text { Systolic BP } \\
(\mathrm{mm} \mathrm{Hg})\end{array}$ & $\begin{array}{l}\text { Diastolic BP } \\
(\mathrm{mm} \mathrm{Hg})\end{array}$ \\
\hline $\begin{array}{l}\text { Positive }(n=10) \text { : } \\
\text { Baseline } \\
\text { Start of syncope }\end{array}$ & $\begin{array}{l}69.6(13.5) \\
86.0(18 \cdot 1)^{\star}\end{array}$ & $\begin{array}{l}146.5(22 \cdot 3) \\
133.4(20 \cdot 0)\end{array}$ & $\begin{array}{l}83 \cdot 0(8 \cdot 0) \\
82 \cdot 7(11 \cdot 3)\end{array}$ \\
\hline $\begin{array}{l}\text { Negative }(n=14): \\
\text { Baseline } \\
\text { End of test }\end{array}$ & $\begin{array}{l}68 \cdot 3(14 \cdot 5) \\
76 \cdot 8(12 \cdot 8)\end{array}$ & $\begin{array}{l}140 \cdot 5(14 \cdot 4) \\
134 \cdot 6(15 \cdot 7)\end{array}$ & $\begin{array}{l}81.9(13.0) \\
83.9(15.5)\end{array}$ \\
\hline
\end{tabular}

malignant vasovagal syncope, ${ }^{5}$ but understanding of the pathophysiology underlying this condition remains poor. The mechanism of syncope is probably similar to the BezoldJarisch reflex. In the face of central hypovolaemia, due either to gravitational effects or to haemorrhage, ventricular diastolic filling may become critically comprised, triggering a cadioprotective reflex involving peripheral vasodilation and bradycardia or asystole. The positive inotropic effect of circulating catecholamines deforms the relatively empty ventricle, triggering mechanoreceptors. ${ }^{6}$ Afferent signals in non-myelinated vagal $C$ fibres cause reflex reduction in sympathetic tone and increased vagal activity. How can the normal control of blood pressure by baroreflexes be overridden by vasovagal mechanisms? Animals studies suggest that endogenous opioids located in the brainstem cardiovascular centres may have an important role. Naloxone, given either intravenously or intracisternally, has been shown to prevent, or reverse, the vasodepressor response in a rabbit model of haemorrhagic shock. ${ }^{7}$ In complementary human studies, with incremental lower body negative pressure, naloxone enhances the cardiopulmonary baroreflex excitation of sympathetic activity. ${ }^{3}$

We have shown a rise in plasma $\beta$ endorphin concentration before the start of symptoms in patients with vasodepressor syncope induced by tilt tests. This contrasts with the remarkably stable plasma $\beta$ endorphin concentrations found in most patients with a negative test. The reports of a rise in plasma arginine vasopressin before vasovagal syn$\operatorname{cope}^{89}$ raise the possibility that neuroendocrine changes play an important part in sensitising left ventricular baroreceptors to circulating catecholamines. In a canine model it has been shown that the systemic and coronary vasoconstriction that follows an intracerebral dose of the opiate agonist fentanyl is mediated through the release of arginine vasopressin. ${ }^{10}$ We have previously shown a correlation between $\beta$ endorphin and arginine vasopressin concentrations in patients with myocardial ischaemia. ${ }^{11}$

After syncope, all patients show a considerable rise in $\beta$ endorphins, consistent with a previous report of patients with vasodepressor syncope secondary to either fasting or to exercise. ${ }^{4}$ This is clearly part of a wider, non-specific neuroendocrine response to the stress of hypotension, with release of cortisol, arginine vasopressin, aldosterone, angiotensin II, and pancreatic polypeptide. ${ }^{8} \mathrm{~A}$ similar large rise in plasma $\beta$ endorphin concentration occurs after hypoglycaemia induced by insulin stress (baseline $5.0 \vee 30$ minutes after hypoglycaemia 19.5). ${ }^{12}$

In conclusion, a rise in plasma $\beta$ endorphins precedes vasodepressor syncope. Endogenous opioid mechanisms seem to be implicated in the pathophysiology of vasodepressor syncope and it is important to examine possible modification of the response with opioid antagonists.

DRW is a British Heart Foundation Friends Providen research follow.

1 Kenny RA, Ingram A, Bayliss J, Sutton R. Head-up tilt: a useful test for investigating unexplained syncope. Lance 1986;i:1352-5.

2 Wallin BG, Sundlof G. Sympathetic outflow to muscles during vasovagal syncope. $\mathcal{F}$ Auton Nerv Syst 1982;6: 287-91.

3 Schobel HP, Oren RN, Mark AL, Ferguson DW Naloxone potentiates cardiopulmonary baroreflex sympathetic control in normal humans. Circ Res 1992;70. 172-83.

4 Perna GP, Ficola U, Salvatori MP, Stanisloa M, Vigna C, Villella A, et al. Increase in plasma beta endorphins in vasodepressor syncope. Am f Cardiol 1990;65:929-30.

5 Fitzpatrick AP, Theodorakis G, Vardas P, Sutton R Methodology of head-up tilt testing in patients with unexplained syncope. $\mathcal{F}$ Am Coll Cardiol 1991;17: 125-30.

6 Thoren P, Skarphedinsson JO, Carlsson S. Sympathetic inhibition from vagal afferents during severe haemorinhibition from vagal afferents during severe haem

7 Evans RG, Ludbrook J, Potocnik SJ. Intracisternal naloxone and cardiac nerve blockade prevent vasodilation during simulated haemorrhage in awake rabbits. F Physio 1989;409:1-14.

8 Sander-Jensen K, Secher NH, Astrup A, Christensen NJ, Giese J, Schwartz TW, et al. Hypotension induced by passive head-up tilt: endocrine and circulatory mechanisms. Am $\mathcal{F}$ Physiol 1986;251:R742-8.

9 Fitzpatrick A, Williams T, Ahmed R, Lightman S, Bloom SR, Sutton R. Echocardiographic and endocrin changes during vasovagal syncope induced by prolonged head-up tilt. European fournal of Cardiac Pacing and Electrophysiology 1992;2:121-8.

10 Pasyk S, Grekin RJ, Walton JA, Pluta W, Pitt B. Mechanism of opiate mediate systemic and coronary vasoconstriction [abstract]. Am $\mathcal{F}$ Cardiol 1982;49:940.

11 Oldroyd KG, Harvey K, Gray CE, Beastall GH, Cobbe SM. $\beta$ endorphin release in patients after spontaneous and provoked acute myocardial ischaemia. Br Heart $\mathcal{f}$ and provoked act

12 Frier BM, Fisher BM, Gray CE, Beastall GH. Counterregulatory hormonal response to hypoglycaemia in type I (insulin dependent) diabetes: evidence for diminished hypothalamic-pituitary hormonal secretion. Diabetologica 1988;31:421-9. 


\section{BRITISH CARDIAC SOCIETY NEWSLETTER}

Many members will have received the letter from Dr Kenneth Calman, the Chief Medical Officer to the Department of Health, on the implementation of the report Hospital doctors: training for the future.

Dr Calman wrote that Ministers had agreed to the full implementation of the report, which encourages the development of a consultant based service. This will shorten training from an average of 12 years to an average of 7 years with more structured and intensive training. The registrar and senior registrar grades will be unified and the finishing point of specialist training will be defined by the Certificate of Completion of Specialist Training (CCST).

Dr Calman recognised that the present rate of expansion of consultant posts $(2 \%)$ needs to be increased. Some existing senior registrar appointments will be upgraded to consultant posts. He emphasised two important conditions: firstly, that there will be no overall increase in NHS resources to fund the changes and, secondly, the need to move away from existing medical staffing policies towards more flexible measures that emphasise "local decision making and priorities".

The NHS Management Executive will be issuing an implementation plan for consultation, but the responsibility for deciding content, direction, and criteria for specialist training rests with individual specialist Royal Colleges and hence through to the SAC in Cardiovascular Medicine and our Training and Manpower Committee. It is important to recognise that the minimum length of training programmes is being reduced but it remains to be seen how much flexibility there will be, especially in terms of funding of the training programmes through the postgraduate deans. During 1994 the General Medical Council will be consulting on the content of general professional training before specialist training.

The letter recognises many difficulties in achieving the change, including the period immediately after the award of a CCST and the introduction of a national numbering system of trainees. These issues are being taken forward by a working group and an implementation steering group. Furthermore, three expert groups are looking at the training of doctors in academic and research medicine, the training of overseas doctors, and the training of general practitioners. Dr Calman envisages that the change to the new structure will be completed within six years. There are many important changes ahead and the Training and Manpower Committee will be working with the British Cardiac Society Council to ensure that six years from now we have excellent training programmes with appropriate numbers of trainees and adequate numbers of consultants to provide the level of specialist care that patients with cardiac disease have a right to expect. Please send any views you have to the British Cardiac Society.

The following two reports from the Join Audit Committee and the European Society of Cardiology make it clear that clinical guidelines will play an increasingly important part in everyday practice-we must al be involved.

\section{Joint Audit Committee BCS/RCP} London

David de Bono writes in defence of clinical standards: but not of cookbooks:

"The NHS Management Executive has recently (and some would say belatedly) become interested in the concept of writing clinical standards into purchaser-provider contracts. Among documents recently circulated to purchasers as possible source material on which to base such standards was a paper on audit guidelines and clinical standards in stable angina prepared as a summary of a workshop held under the auspices of the Joint Audit Committee of the British Cardiac Society and the Royal College of Physicians of London. The Joint Audit Committee has since held a further workshop on acute myocardial infarction and intends shortly to hold workshops on heart failure, arrhythmias, and valvar heart disease. Is this an attempt to curb the rich diversity of British cardiological practice by imposing rigid guidelines or cookbook protocols? Emphatically not! There is increasing recognition by all parties, not least by purchasers, that the only guidelines likely to be followed-and therefore effective-are those drawn up locally with the involvement of all interested parties including general practitioners with a full understanding of local problems and resources. The two main objectives of the Joint Audit Committee summaries are firstly to provide a brief but accurate description of the clinical condition and a synopsis of recent clinical trial data and second to identify essential features that need to be recorded so that clinical practice can be audited. If clinicians can use this material to help them draw up local guidelines, then our aim will have been fulfilled. In practice, no one can or should expect absolute compliance even with local guidelines: this would be robotics not medicine. On the other hand, clinicians who depart from locally agreed guidelines should be prepared to justify their action and, even more important, to record their results. When I started in cardiology I was taught to use 8 gauge catheters, always to do a left ventricular angiogram, always to heparinise the patient, and to keep cathete patients in hospital overnight (if not for three or four days). I now do none of these Changes in management of myocardial infarction, arrhythmias and heart failure have been even more spectacular. But there is no point in being an innovator unless process and outcome are properly recorded so that they can be independently checked, compared with conventional wisdom and, if better, communicated efficiently to others. Purchasers will increasingly seek to write audit funding into individual contracts rather than to deliver it as a lump sum; they can be educated to see properly audited innovation as being essential to their own interests as well as those of the provider."
European Society of Cardiology

Philip Poole-Wilson writes: "Some of you are involved in working groups that prepare guidelines, academic comments or policy statements on areas of interest in cardiology. The Board of the European Society of Cardiology has clarified how these activities should be classified. A task force is established by the board to prepare recommendations or guidelines. Task forces can be proposed to the board by working groups, national societies, or others. The final document needs endorsement by the Board of the European Society of Cardiology and will be published in the European Heart fournal. Study groups can be established by working groups of the European Society of Cardiology to look into specific topics and to prepare opinions and recommendations. These reports reflect the opinions of the study groups and working group. Ideally reports from study groups should be submitted to the European Heart fournal and they almost certainly will be subjected to the normal reviewing process. I do hope that many of you will join task forces or study groups. If there are topics that you think should be evaluated in the context of a working group of the European Society of Cardiology do suggest that to the chairmen of those working groups.

\section{Forthcoming meetings}

Jarda Stark is due to give his Tudor Edwards Lecture entitled "Quo vadis paediatric cardiac surgery" on 2 June 1994 at $5.00 \mathrm{pm}$ at the Royal College of Surgeons of England, 35/43 Lincoln's Inn Fields, London. For further information telephone 0714053474.

A second meeting on Cardiovascular Disease Prevention will be held on the 19-22 July 1994 at the Conference Centre, Kensington Town Hall, London. Please contact Hampton Medical Conferences Limited, Hofer House, 185 Uxbridge Road, Hampton, Middiesex (tel: 081783 0810) for further information.

D JOHN PARKER President, British Cardiac Society IOHN G F CLELAND Assistant Secretary, British Cardiac Society,
9 Fitzroy Square, London WIP $5 A H$ NOTICE

The 1995 Annual Meeting of the British Cardiac Society will take place at the Conference Centre, Harrogate, West Yorkshire from 23 to 25 May.

\section{CORRECTION}

ncrease in plasma $\beta$ endorphins precedes vasodepressor syncope $D R$ Wallbridge, $H E$ MacIntyre, $C E$ Gray, $M A$ Denvir, K G Oldroyd, A P Rae, S M Cobbe. We regret that owing to a printers' error all four figures in this article in the May issue (Br Heart 7 1994;71:446-8) appeared in the wrong order and with wrong legends. The corrected version of the article is reprinted on pages $597-599$ of this issue. 


\title{
Increase in plasma $\beta$ endorphins precedes vasodepressor syncope
}

\author{
David R Wallbridge, Halina E MacIntyre, Christina E Gray, Martin A Denvir, \\ Keith G Oldroyd, Alan P Rae, Stuart M Cobbe
}

\begin{abstract}
Background-Endogenous opioids have a tonic inhibitory effect on sympathetic tone and have been implicated in the pathophysiology of vasodepressor syncope. Plasma $\beta$ endorphin concentrations increase after vasodepressor syncope induced by exercise or by fasting.

Aims-To take frequent samples for plasma $\beta$ endorphin estimation during tilt testing, and to determine whether plasma $\beta$ endorphin increased before the start of syncope.
\end{abstract}

Patients -24 patients undergoing tilt testing for investigation of unexplained syncope.

Setting-Tertiary referral centre.

Methods-Blood samples were obtained during $70^{\circ}$ head up tilt testing. Plasma $\beta$ endorphin concentrations were estimated by radioimmunoassay (mean(SD) pmol/1).

Results-Patients with a positive test showed a rise in $\beta$ endorphin concentrations before syncope (baseline $4 \cdot 4(1 \cdot 5) v$ start of syncope $8 \cdot 5(3 \cdot 1)$, p < 0.002). In contrast, patients with a negative test showed no change in $\beta$ endorphin concentrations (baseline $3 \cdot 4(1.0) v$ end of test $4 \cdot 5(2 \cdot 3)$, NS). After syncope all patients showed a large secondary increase in $\beta$ endorphins $(32 \cdot 3(18 \cdot 6))$.

Conclusion-An increase in plasma $\beta$ endorphins precedes vasodepressor syncope. This finding supports a pathophysiological role for endogenous opioids.

(Br Heart f 1994;71:597-599)

Department of Medical Cardiology

D R Wallbridge

M A Denvir

K G Oldroyd

A P Rae

$S M$ Cobbe

Department of Pathological

Biochemistry, Royal

Infirmary, Glasgow

HE MacIntyre

C E Gray

Correspondence to:

Dr D R Wallbridge,

Department of Medical

Cardiology, Royal Infirmary,

Cardiology, Royal inf

G Alexandra Parase,

Accepted for publication

22 November 1993 multiple potential causes. Vasodepressor (neurocardiogenic) syncope is being increasingly recognised with the introduction of head up tilt testing. ${ }^{1}$ Although the pathophysiology of this condition is not fully elucidated, hypotension probably results from a sudden reduction in or cessation of sympathetic activity. $^{2}$ Endogenous opioids seem to exert a tonic inhibitory effect on sympathetic responses to orthostatic stress, and have been implicated in the mechanisms underlying syncope. ${ }^{3}$ Plasma $\beta$ endorphins have previously been shown to rise in patients after vasodepressor syncope but it is unclear whether this represents a pri- mary or secondary phenomenon. ${ }^{4}$ Therefore, we performed frequent blood sampling for plasma $\beta$ endorphin estimation during tilt tests, to establish whether plasma $\beta$ endorphins are released before the onset of syncope.

\section{Patients and methods}

TILT TEST

We studied 24 consecutive patients (mean (range) age 54.5 (18-77)) undergoing tilt tests for the investigation of unexplained syncope. Table 1 shows the clinical characteristics of the patients. Regular medication was continued before the test. All tests were performed in the fasting state between 0930 and 1230. Patients were tilted $70^{\circ}$ head upwards for up to 40 minutes: an angle of at least $60^{\circ}$ was required for adequate test sensitivity. ${ }^{5}$ Non-invasive measurement of blood pressure was performed with Finapress (continuous) and Dinamapp (intermittent) devices. An antecubital venous cannula, inserted $15 \mathrm{~min}$ utes before the test, allowed frequent blood sampling. Aliquots of $20 \mathrm{ml}$ were obtained at baseline, and then every 10 minutes, or at the start of symptoms, and after syncope (a maximum of $120 \mathrm{ml}$ per test).

\section{ENDORPHIN ASSAY}

$\beta$ Endorphin was measured by an in house liquid phase radioimmunoassay after extraction from plasma with C18 Sep-Pak cartridges. The primary antiserum cross reacts by $2 \%$ with human $\beta$ lipotrophin (Peninsula Laboratories) and by $<0.01 \%$ with other related peptides. The sensitivity of the assay is $2 \mathrm{pmol} / \mathrm{l}$. The within batch coefficient of variation over the concentration range 12 to 60 $\mathrm{pmol} / 1$ was $5 \%$, and $10 \%$ at $7 \mathrm{pmol} / 1$. The between batch variation for corresponding ranges was $8 \%$ and $12 \%$. Results are given as mean(SD) plasma $\beta$ endorphin concentrations expressed as $\mathrm{pmol} / \mathrm{l}$.
Table 1 Clinical characteristics of patients by tilt test result

\begin{tabular}{lll}
\hline & Positive tilt test & Negative tilt test \\
\hline No & 10 & 14 \\
M/F & $7 / 3$ & $6 / 8$ \\
Age (yr) & $54 \cdot 5(15 \cdot 9)$ & $55 \cdot 5(14 \cdot 5)$ \\
Previous myocardial & 1 & \\
$\quad$ infarction & 1 & 2 \\
Hypertension & 3 & 4 \\
$\beta$ Blocker or disopyramide & 1 & 2 \\
\hline
\end{tabular}


Figure 1 Plasma $\beta$ endorphin concentrations in patients with a positive tilt test (syncope $=$ time 0). Broken line is upper limit of normal

Figure 2 Plasma $\beta$ endorphin concentrations in patients with a negative tilt test. Broken line is upper limit of normal.

Figure 3 Plasma $\beta$ endorphin concentrations before and after syncope. Broken line is upper limit of normal.
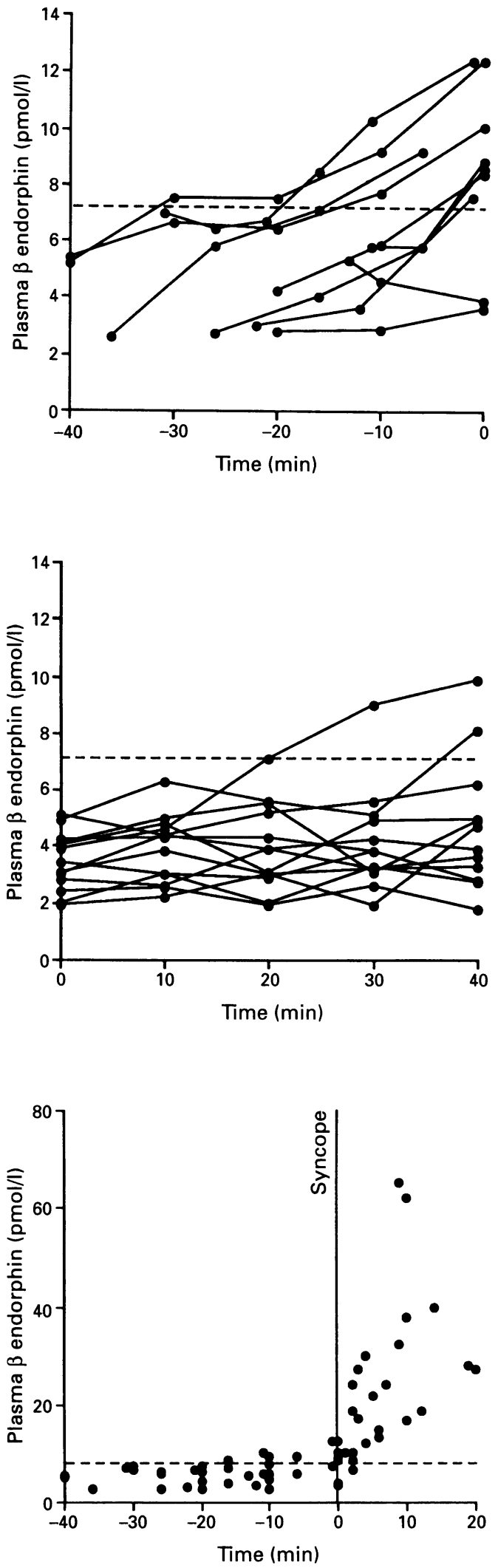

Results

PLASMA $\beta$ ENDORPHIN CONCENTRATIONS

Patients with a positive test (nine vasodepressor syncope; one presyncope: mean time to onset $26.1 \mathrm{~min}$ ) showed a significant rise in plasma $\beta$ endorphin concentrations before syncope (baseline $4 \cdot 4(1 \cdot 5) v$ start of syncope $8.5(3.1), \mathrm{p}<0.002)$. A rise in plasma $\beta$ endorphin concentrations to above the upper limit of normal $(7 \cdot 2)$ occurred before the start of symptoms in eight of these 10 patients (fig 1 ).

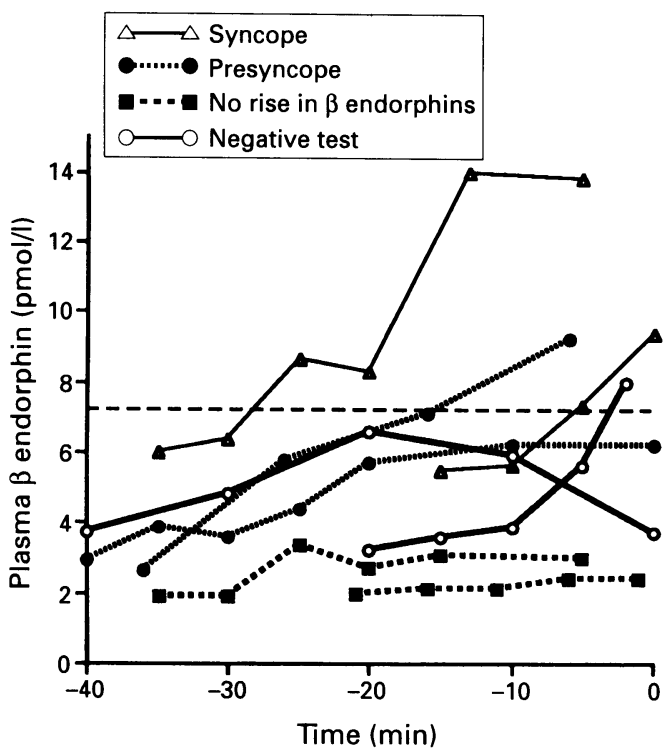

Figure 4 Plasma $\beta$ endorphin responses on repeat tilt tests in four patients with vasodepressor syncope. Concordant responses include syncope, presyncope on repeat testing, no rise in plasma $\beta$ endorphins before two vasodepressor responses. After successful treatment with disopyramide one patient had a negative test (syncope or end of test = time 0 ). Broken line is upper limit of normal.

In contrast, the group of patients with a negative test showed little change in plasma $\beta$ endorphin concentrations during the haemodynamic stress of tilting (baseline $3 \cdot 4(1 \cdot 0) v$ end of test $4 \cdot 5(2 \cdot 3)$, NS). Only two of 14 patients with a negative test showed a rise in plasma $\beta$ endorphin concentrations to above the upper limit of normal (fig 2).

When samples were obtained during syncope, four patients showed a small fall in plasma $\beta$ endorphin concentrations corresponding to the nadir of blood pressure. This fall was not accompanied by parallel changes in human growth hormone, as might be expected from pituitary hypoperfusion. After syncope all patients showed a large secondary increase in plasma $\beta$ endorphins (32.3(18.6), (fig 3).

\section{REPRODUCIBILITY OF THE ENDORPHIN} RESPONSE

Figure 4 shows the plasma $\beta$ endorphin response during repeat tilt testing in four patients with vasodepressor syncope. The concordant responses include one patient with syncope, one patient with presyncope on repeat tests, and one patient with no rise in plasma $\beta$ endorphins before vasodepressor syncope on two occasions. Successful treatment with disopyramide in one patient resulted in a negative tilt test with no sustained rise in $\beta$ endorphin.

HAEMODYNAMIC RESPONSE BEFORE SYNCOPE

Table 2 shows the haemodynamic response to tilt tests. Although there was a wide scatter of results, and a borderline significant rise in heart rate before syncope in the positive test group, no significant differences existed at any time between the heart rates or blood pressures in the positive or negative test groups. 
Table 2 Haemodynamic response to tilt tests (mean (SD))

\begin{tabular}{llll}
\hline$n$ & $\begin{array}{l}\text { Heart rate } \\
\text { (beats/min) }\end{array}$ & $\begin{array}{l}\text { Systolic BP } \\
(\mathrm{mm} \mathrm{Hg})\end{array}$ & $\begin{array}{l}\text { Diastolic BP } \\
(\mathrm{mm} \mathrm{Hg})\end{array}$ \\
\hline $\begin{array}{l}\text { Positive }(\mathrm{n}=10): \\
\text { Baseline }\end{array}$ & $69.6(13.5)$ & $146.5(22.3)$ & $83.0(8.0)$ \\
$\quad$ Start of syncope & $86.0(18.1)^{\star}$ & $133.4(20.0)$ & $82.7(11.3)$ \\
Negative $(\mathrm{n}=14):$ & & & \\
$\quad$ Baseline & $68.3(14.5)$ & $140.5(14.4)$ & $81.9(13.0)$ \\
$\quad$ End of test & $76.8(12.8)$ & $134.6(15.7)$ & $83.9(15.5)$ \\
\hline
\end{tabular}

${ }^{\star} \mathrm{p}<0.04 v$ Baseline (positive); NS $v$ end of test (negative).

\section{Discussion}

Tilt testing has facilitated the diagnosis of malignant vasovagal syncope, ${ }^{5}$ but understanding of the pathophysiology underlying this condition remains poor. The mechanism of syncope is probably similar to the BezoldJarisch reflex. In the face of central hypovolaemia, due either to gravitational effects or to haemorrhage, ventricular diastolic filling may become critically compromised, triggering a cadioprotective reflex involving peripheral vasodilation and bradycardia or asystole. The positive inotropic effect of circulating catecholamines deforms the relatively empty ventricle, triggering mechanoreceptors. ${ }^{6}$ Afferent signals in non-myelinated vagal $C$ fibres cause reflex reduction in sympathetic tone and increased vagal activity. How can the normal control of blood pressure by baroreflexes be overridden by vasovagal mechanisms? Animals studies suggest that endogenous opioids located in the brainstem cardiovascular centres may have an important role. Naloxone, given either intravenously or intracisternally, has been shown to prevent, or reverse, the vasodepressor response in a rabbit model of haemorrhagic shock. ${ }^{7}$ In complementary human studies, with incremental lower body negative pressure, naloxone enhances the cardiopulmonary baroreflex excitation of sympathetic activity. ${ }^{3}$

We have shown a rise in plasma $\beta$ endorphin concentration before the start of symptoms in patients with vasodepressor syncope induced by tilt tests. This contrasts with the remarkably stable plasma $\beta$ endorphin concentrations found in most patients with a negative test. The reports of a rise in plasma arginine vasopressin before vasovagal syncope $^{89}$ raise the possibility that neuroendocrine changes play an important part in sensitising left ventricular baroreceptors to circulating catecholamines. In a canine model it has been shown that the systemic and coronary vasoconstriction that follows an intracerebral dose of the opiate agonist fentanyl is mediated through the release of arginine vasopressin. ${ }^{10}$ We have previously shown a correlation between $\beta$ endorphin and arginine vasopressin concentrations in patients with myocardial ischaemia. ${ }^{11}$

After syncope, all patients show a considerable rise in $\beta$ endorphins, consistent with a previous report of patients with vasodepressor syncope secondary to either fasting or to exercise. ${ }^{4}$ This is clearly part of a wider, non-specific neuroendocrine response to the stress of hypotension, with release of cortisol, arginine vasopressin, aldosterone, angiotensin II, and pancreatic polypeptide. ${ }^{8} \mathrm{~A}$ similar large rise in plasma $\beta$ endorphin concentration occurs after hypoglycaemia induced by insulin stress (baseline $5.0 \vee 30$ minutes after hypoglycaemia 19.5)..$^{12}$

In conclusion, a rise in plasma $\beta$ endorphins precedes vasodepressor syncope. Endogenous opioid mechanisms seem to be implicated in the pathophysiology of vasodepressor syncope and it is important to examine possible modification of the response with opioid antagonists.

DRW is a British Heart Foundation Friends Provident research follow.

1 Kenny RA, Ingram A, Bayliss J, Sutton R. Head-up tilt: a useful test for investigating unexplained syncope. Lancet 1986;i:1352-5.

2 Wallin BG, Sundlof G. Sympathetic outflow to muscles during vasovagal syncope. F Auton Nerv Syst 1982;6: 287-91.

3 Schobel HP, Oren RN, Mark AL, Ferguson DW. pathetic control in normal humans. Circ Res 1992;70: pathetic

4 Perna GP, Ficola U, Salvatori MP, Stanisloa M, Vigna C, Villella $A$, et al. Increase in plasma beta endorphins in vasodepressor syncope. Am f Cardiol 1990;65:929-30.

5 Fitzpatrick AP, Theodorakis G, Vardas P, Sutton R. Methodology of head-up tilt testing in patients with unexplained syncope. $\mathcal{F}$ Am Coll Cardiol 1991;17: 125-30.

6 Thoren P, Skarphedinsson JO, Carlsson S. Sympathetic inhibition from vagal afferents during severe haemorrhage in rats. Acta Physiol Scand 1988;571:97-105.

7 Evans RG, Ludbrook J, Potocnik SJ. Intracisternal naloxone and cardiac nerve blockade prevent vasodilation during simulated haemorrhage in awake rabbits. $f$ Physiol 1989;409:1-14.

8 Sander-Jensen K, Secher NH, Astrup A, Christensen NJ, Giese J, Schwartz TW, et al. Hypotension induced by passive head-up tilt: endocrine and circulatory mecha-
nisms. Am $¥$ Physiol 1986;251:R742-8.

9 Fitzpatrick A, Williams T, Ahmed R, Lightman S, Bloom SR, Sutton R. Echocardiographic and endocrine SR, Sutton $R$. Echocardiographic and endocrine
changes during vasovagal syncope induced by prolonged changes during vasovagal syncope induced by prolonged head-up tilt. European fournal

10 Pasyk S, Grekin RJ, Walton JA, Pluta W, Pitt B. Mechanism of opiate mediate systemic and coronary vasoconstriction [abstract]. Am f Cardiol 1982;49:940.

11 Oldroyd KG, Harvey K, Gray CE, Beastall GH, Cobbe $\mathrm{SM} . \beta$ endorphin release in patients after spontaneous and provoked acute myocardial ischaemia. Br Heart $\mathcal{F}$ 1992;67:230-5.

12 Frier BM, Fisher BM, Gray CE, Beastall GH. Counterregulatory hormonal response to hypoglycaemia in type I (insulin dependent) diabetes: evidence for diminished hypothalamic-pituitary hormonal secretion. Diabetologica 1988;31:421-9. 